\title{
ИСПОЛЬЗОВАНИЕ ОФШОРНЫХ КОМПАНИЙ В ЦЕЛЯХ ПРОВЕДЕНИЯ СОМНИТЕЛЬНЫХ ФИНАНСОВЫХ ОПЕРАЦИЙ И ПРАВОВЫЕ РИСКИ КОНТРАГЕНТОВ ДАННЫХ КОМПАНИЙ
}

\begin{abstract}
Аннотация: В настоящей статье, составленной на основе реферата, подготовленного в качестве выпускного материала по итогам обучения на факультативе по курсу «Безопасность предпринимательской деятельности», автор рассматривает правовые аспекты бизнеса с использованием офшорных компаний и правовые риски, возникающие у контрагентов данных компаний. Данный материал позволяет будущим специалистам в области корпоративного права узнать сферу деятельности, представляюшую репутационные риски для добросовестного бизнеса, а также возможность использования российских компаний в действиях, направленных на возможную легализацию доходов, полученных преступным путем, и соответствуюших правовых последствиях таких ситуаций.
\end{abstract}

Ключевые слова: Юриспруденция, офшорные зоны, минимизаиия налогообложения, отмывание доходов, финансирование терроризма, фирмы-однодневки, правовые риски, репутационные риски, контрагенты, противоправная деятельность

\section{Введение}

овременные офшорные зоны предоставляют значительный простор для совершения самого разного рода правонарушений участниками предпринимательской деятельности. И этому есть вполне логичное обоснование - сталкиваясь с постоянными административными препонами на всех стадиях предпринимательской деятельности (от учреждения юридического лица, до исчисления и уплаты налогов) даже принципиально законопослушные лица, принимающие решения в хозяйственных обществах, все чаще рассматривают различные оффшорные схемы, как один из вариантов дальнейшей деятельности. И действительно, быстрая регистрация в стране-офшоре, свободное и минимальное налогообложение делают офшорные схемы еще более привлекательными.

Однако чаще всего офшорные зоны используются не от безысходности предпринимателей, а в целях максимизации прибыли путем уклонения от уплаты законно установленных налогов, либо в целях легализации доходов, полученных преступным путем.

Стремление уменьшить отток капитала со стороны государства через компании, зарегистрированные в офшорных зонах, обусловлено тем, что офшорные зоны используются как инструмент уклонения от уплаты налогов и отмывания денег, полученных преступным путем.
В данной работе будут рассмотрены основные способы использования оффшорных зон в современном мире, а также правовые риски, которые может нести контрагент компании-офшора, осуществляющий деятельность на территории Российской Федерации.

\section{Понятие и преимущества офшорных сделок}

Понятие «офшорная зона» обозначает государство или территорию, предусматривающие льготный режим налогообложения и (или) не предусматривающие раскрытия и представления информации при проведении финансовых операций. ${ }^{1}$

Офшорные компании, в большинстве случаев, создаются на территории небольших государств, с невысоким уровнем развития собственной экономики, но с достаточно высокой политической стабильностью (Багамские острова, Британские Виргинские острова, Вануату, Сейшельские острова и т.д.). Как правило, эти государства не предъявляют никаких требований к отчетности, единственное требование - это внести, как правило, ежегодный фиксированный сбор в казну. В России завоевали популярность как офшоры Кипр, Ирландия, Гибралтар, Люксембург, Швейцария, Остров Мэн и др. ${ }^{2}$

\footnotetext{
${ }^{1}$ Приказ Министерства финансов России от 13.11.2007 N 108н

2 Удалов Р. Чем рискует контрагент офшорной компании // Налоги и налоговое планирование. 2011. N 5. С. 19
} 


\section{Национальная безопасность $1(24) \cdot 2013$}

Основной особенностью офшорных компаний является то, что присутствие компании в стране регистрации является номинальным. Данные компании, как правило, не ведут деятельность в стране регистрации, не имеют в этой стране офиса, штата сотрудников, управление такой компанией производится из-за рубежа, собственники данных компаний также не являются резидентами офшорных стран ${ }^{3}$. Соответственно, собственники таких компаний уклоняются от налогообложения в стране, где фактически осуществляется их деятельность. Модели уклонения от уплаты налогов с использованием офшорных компаний различны. В основном данные компании действуют не самостоятельно, а в цепочке компаний (возможно, фирмоднодневок), управляемых одним владельцем.

Офшорные компании представляют ряд преимуществ хозяйствующим субъектам при планировании и осуществлении предпринимательской деятельности. В частности, привлекательными являются следующие моменты ${ }^{4}$ :

- упрощенная процедура регистрации: минимальные требования к размеру уставного капитала, конфиденциальный режим личной информации;

- н низкие налоговые ставки, а в некоторых офшорных зонах - отсутствие налога на прибыль;

- фактическое отсутствие валютных ограничений, возможность осуществления банковских и иных операций в любой валюте;

- дополнительные льготы для инвесторов, которые предоставляют офшорные зоны;

- высокий уровень коммерческой секретности и анонимность реальных владельцев компании, которые реализуются посредством номинальных владельцев и номинальных директоров. Раскрытие информации в отношении реальных владельцев (директоров) фактически невозможно, так как некоторые офшорные зоны практикуют выпуск акций на предъявителя;

- стабильность экономико-политического режима, так как в основном в течение не менее 15 лет с момента регистрации офшорной компании инвестору гарантируется неизменность условий осуществления предпринимательской деятельности ${ }^{5}$.

\footnotetext{
3 Удалов Р. Чем рискует контрагент офшорной компании // Налоги и налоговое планирование. 2011. N 5. С. 19.

${ }^{4}$ Гаврилова С. Офшоры: особенности правового регулирования // Финансовая газета. 2011. N 29. С. 12.

${ }^{5}$ Гаврилова С. Офшоры: особенности правового регулирования // Финансовая газета. 2011. N 29. С. 12.
}

Нужно отметить, что Российская Федерация не может бороться с офшорными компаниями «топорными» методами - запрещать деятельность на территории РФ или устанавливать особые условия для их деятельности, поскольку в соответствии с декларированным Российской Федерацией принципом гарантирования национального режима для иностранных инвестиций, мы не имеем никаких прав дискриминировать инвестиции из каких-либо стран или регионов лишь по причине того, что в указанных странах существуют более льготные режимы налогообложения. ${ }^{6}$ Соответственно сам факт осуществления предпринимательской деятельности с помощь посредством использования контрагентов-офшоров еще не служит основанием для применения мер административной, налоговой или уголовной ответственности. Данные меры применяются только при установлении факта совершения запрещенных законом действий с помощью офшорных компании.

В следующей главе мы подробнее рассмотрим основные способы использования офшорных зон.

\section{Способы использования офшорных схем}

Наиболее частой причиной использование компании-офшора является стремление минимизировать налоги, занизив налогооблагаемую базу. Соответственно, первый способ использования офшорной компании связан непосредственно с уклонением от уплаты налогов. Данный способ заключается в открытии подконтрольной офшорной компанией банковского счета. Соответственно, на этот банковский счет либо осуществляются переводы с остальных подконтрольных правонарушителю юридических лиц в качестве платы за какие-либо услуги, либо сама предпринимательская деятельность осуществляется путем использования открытого в офшорной юрисдикции банковского счета и контрагенты по реальным договорам вынуждены оплачивать счета через данный расчетный счет.

Основное назначение указанного способа - минимизация налога на прибыль с организаций за счет того, что достигается значительное увеличение расходов и организация, зарегистрированная на территории РФ и являющаяся российским налогоплательщиком показывает близкую к нулевой прибыльность.

Однако нужно отметить, что данный способ использования офшорной юрисдикции для мини-

\footnotetext{
${ }^{6}$ Письмо Минфина РФ от 23.02.1998 N 04-06-02.
} 
мизации налогового бремени был эффективен и повсеместно распространен в 1990-е годы. В настоящее время он почти не применяется, поскольку было усилено государственное регулирование в рамках ПОД/ФТ (противодействия отмыванию доходов, полученных преступным путем, и финансированию терроризма). На данный момент установлена обязанность для кредитных организаций информирования Росфинмониторинга о совершении подозрительных финансовых операций. Критерии подозрительности финансовых операций на законодательном уровне не определены, однако Банк России в своих письмах регулярно устанавливает тот или иной критерий подозрительности финансовой операции. В соответствии с указаниями Банка России «подозрительными» считаются операции, характеризуемые следующими признаками:

- денежные средства переводятся на счета, как правило, в кредитные организации Республики Казахстан, Республики Молдова, Эстонской Республики, Латвийской Республики, Республики Кипр;

- организации-клиенты имеют невысокий уставный капитал, более чем в 100 раз ниже объема ежемесячно переводимых ими за границу денежных средств;

- операции имеют транзитный характер - поступившие денежные средства практически в полном объеме переводятся за границу;

- уплата налогов со счетов таких клиентов переводится в бюджет в размере менее $2 \%$ суммы средств, переводимых за границу ${ }^{7}$.

Банк России считает, что наличие перечисленных признаков свидетельствует в данном случае о желании уклониться от уплаты налогов, оплате «серого» импорта и об отмывании доходов, полученных преступным путем ${ }^{8}$.

Соответственно, если организация предполагает использовать офшорную компанию с банковским счетом в свободной от государственного контроля юрисдикции, то ей нужно позаботиться о соответствующем документальном обеспечении и приготовится к возможным проверкам деятельности, а также к постоянной блокировке операций российскими кредитными организациями. В связи с такими сложностями рассмотренная выше схема постепенно отмирает.

\footnotetext{
${ }^{7}$ Прудников П.В., Банк России вновь призывает коммерческие банки усилить контроль за клиентами, Новое в бухгалтерском учете и отчетности, 2008, N 21//СПС Консультант Плюс

${ }^{8}$ Прудников П.В., Банк России вновь призывает коммерческие банки усилить контроль за клиентами, Новое в бухгалтерском учете и отчетности, 2008, N 21//СПС Консультант Плюс
}

Второй способ минимизации налогов и иных обязательных платежей - это совместное учреждение российской и офшорной компаниями предприятия на территории РФ и внесение определенного имущества офшорной компании в уставной капитал ${ }^{9}$. Как правило, такая схема является одноразовой и применяется, если необходимо ввезти на территорию России дорогостоящее оборудование и минимизировать таможенные платежи и ввозной НДС. В связи с этим сложно признать данную схему несущей значительную угрозу экономики РФ.

Третий способ минимизации налогообложения - использование подконтрольной офшорной компании в экспортно-импортных операциях. Так, покупка напрямую офшорной компанией интересующего иностранного реального контрагента товара позволяет сэкономить на НДС, чего не было, если бы российская компания сама закупила в РФ товар для экспортных целей и впоследствии экспортировала его для передачи контрагенту ${ }^{10}$.

Существует специфическая схема использования офшорных компаний в страховом бизнесе, связанная не только с минимизацией налогового бремени, но и с выводом денежных средств с территории РФ. Так, российская страховая компания может использовать договор перестрахования собственных рисков в подконтрольной офшорной компании и таким образом переводить в офшорные юрисдикции значительные финансовые суммы. В современном законодательстве практически не предусмотрены барьеры для указанного способа выведения денежных средств из территории страны, за исключением налога на прибыль иностранных организаций, однако если подконтрольная оффшорная компания зарегистрирована в государстве, с которым у России имеется соглашение об избежании двойного налогообложения (например, республика Кипр), то даже налоговые барьеры не работают.

\section{Правовые риски контрагентов офшорных компаний}

Ввиду постоянного совершенствования средств и способов государственного контроля за соверше-

\footnotetext{
${ }^{9}$ Павлов П.В. Офшорная деятельность: вопросы правовой регламентации // Журнал российского права. 2011. N 5. // СПС Консультант Плюс

${ }^{10}$ Павлов П.В. Офшорная деятельность: вопросы правовой регламентации // Журнал российского права. 2011. N 5. // СПС Консультант Плюс
} 


\section{Национальная безопасность 1(24) • 2013}

нием финансовых операций контрагенты фирм, зарегистрированных в офшорной юрисдикции, несут значительные правовые риски. Причем этим рискам подвержены не только компании, намеренно использующие офшоры для совершения сомнительных финансовых операций, но и добросовестные контрагенты, осуществляющие свою предпринимательскую деятельность в прямом соответствии с ее значением, установленным в Гражданском кодексе РФ (далее - ГК РФ) - а именно с целью извлечения прибыли, и которые, если следовать логике ГК РФ, не должны были бы уделять особое внимание личности или происхождению своих контрагентов.

Правовые риски можно условно разделить на 4 большие группы: гражданско-правовые риски, налоговые риски, административные риски и уголовные риски. Рассмотрим данные категории рисков подробнее.

Гражданско-правовые риски взаимодействия с офшорными компаниями заключаются в затруднении способов судебной защиты своих интересов в случае неисполнения контрагентом-офшором своих обязательств. Как правило, офшорные компании, если они не подконтрольны самому российскому хозяйствующему субъекту, в случае совершения реальных операций с добросовестными контрагентами стремятся подчинить заключаемые договоры праву страны собственной регистрации. Делается это для того, чтобы в случае возникновения спора дело рассматривалось в стране, к юрисдикции которой относится офшорная компания. Это позволяет обеспечить нужное офшорной компании судебное решение (ввиду значительного уровня коррупции в правоохранительных и судебных органах офшорных государств), а чаще всего таким образом обеспечивается отсутствие вообще судебного решения, поскольку контрагенты приходят к выводу, что оплата юридических услуг, связанных с изучением законодательства страны офшора, командирования своего представителя и осуществление самого представительства в суде требует затрат, которые могут оказаться значительнее затрат, вызванных неисполнением договора офшорной фирмой.

Если же договор все же подчиняется российскому праву, то нужно тщательно проверять личный статус контрагента, поскольку согласно нормам международного частного права и в частности статье 2102 ГК РФ личный статус юридического лица определяется по законодательству страны инкорпорации (то есть создания юридического лица). Соответственно, если согласно законодательству офшорной юрисдикции фирма зарегистрирована с нарушениями, позволяющими признать данную регистрацию недействительной, то договор, заключенный с данным юридическим лицом будет признаваться судами также недействительным, что может повлечь значительные убытки, поскольку осуществить двустороннюю реституцию в отношении имущества, переданного офшорной компании в отсутствии желания этой самой компании практически невозможно: даже в Российской Федерации исполнительная система работает неэффективно и не может обеспечить исполнение вынесенных судебных решений, тогда как в офшорных странах исполнительная система зачастую вообще отсутствует в структуре органов государственной власти.

Следующая группа рисков при сделках с офшорными контрагентами - налоговые. Здесь можно подробнее остановиться на двух видах налоговых рисков.

Первый вид - непредвиденные налоговые обязательства. Они как правило возникают в схемах, когда офшорная компания предоставляет российской компании займ и рассчитывает на получение через определенное время тела займа вместе с процентами ${ }^{11}$. Эти сделки могут быть как реальными (в этом случае величина процентов не намного отличается от среднерыночной цены займа), так и осуществляться в целях вывода капитала из страны - в этом случае размер возвращаемых процентов значительно превышает сумму «тела» займа. Однако в обоих случаях в соответствии с пп. 3 п. 1 ст. 309 Налогового кодекса Российской Федерации необходимо будет удержать налог у источника в Российской Федерации, что не всегда прогнозируется при осуществлении подобных операций ${ }^{12}$.

Второй вид налоговых рисков - возникновение налоговой обязанности у лица, которое изначально не рассматривалось субъектом таковой при планировании деятельности участников офшорных правоотношений ${ }^{13}$. Например, если физическое лицо гражданин США (либо иного государства, в котором действует правило $\mathrm{CFC}$ - controlled foreign company, или контролируемые иностранные компании) является учредителем офшорной компании, то при определенных обстоятельствах доход, полученный

\footnotetext{
11 Удалов Р. Чем рискует контрагент офшорной компании // Налоги и налоговое планирование. 2011. N 5. С. 20

12 Удалов Р. Чем рискует контрагент офшорной компании // Налоги и налоговое планирование. 2011. N 5. С. 20

13 Удалов Р. Чем рискует контрагент офшорной компании // Налоги и налоговое планирование. 2011. N 5. С. 22
} 
данной компанией, будет включаться в налоговую базу физического лица. В настоящее время правило CFC действует в большинстве развитых государств (США, Великобритания, Нидерланды, Португалия, Франция и др. $)^{14}$. Если данное правило будет введено в Российской Федерации, то российским бенефициарам придется декларировать и облагать налогом в Российской Федерации доходы своих офшоров.

Административные риски могут быть связаны либо с привлечением к административной ответственности. Привлечение к административной ответственности за правонарушения в сфере налогов и сборов для участника офшорных правоотношений наиболее вероятно в следующих ситуациях:

- офшорная компания ведет деятельность, приводящую к возникновению постоянного представительства в Российской Федерации, с нарушением срока постановки на учет ${ }^{15}$;

- офшорная компания ведет деятельность, приводящую к возникновению постоянного представительства в Российской Федерации, и при этом она не подает налоговую декларацию ${ }^{16}$;

- офшорная компания не предоставляет сведения, необходимые для осуществления налогового контроля. ${ }^{17}$

Субъектом вышеупомянутых правонарушений может быть только должностное лицо (директор офшорной компании).

И, наконец, самые серьезные риски - риски уголовные. Данные риски могут возникать в силу норм нескольких статей Уголовного кодекса Российской Федерации (далее - УК РФ). В первую очередь, это статьи 198-199 - уклонение от уплаты налогов с физических лиц и организаций. Ответственность по данной статье может быть применена прежде всего к генеральному директору и главному бухгалтеру российской компании, сотрудничающей с офшорной компанией. Однако здесь важна сумма налогов, не уплаченная в бюджет.

В последние годы активно применяются статьи 174 и 174.1 - легализация доходов, полученных пре-

14 Удалов Р. Чем рискует контрагент офшорной компании // Налоги и налоговое планирование. 2011. N 5. С. 22

${ }^{15}$ Кодекс Российской Федерации об административных правонарушениях от 30.12.2001 N 195-Ф3, ст. 15.3

${ }^{16}$ Кодекс Российской Федерации об административных правонарушениях от 30.12.2001 N 195-Ф3, ст.15.5

${ }^{17}$ Кодекс Российской Федерации об административных правонарушениях от 30.12.2001 N 195-Ф3, ст. 15.6 ступным путем. Данные статьи применяются, как правило, к генеральным директорам российских компаний, если они были осведомлены о преступном источнике переводимых денежных средств.

Таким образом, подводя итоги главы, нужно отметить, что и самостоятельное использование офшорных компаний в планировании собственной деятельности, и добросовестность в отношениях с офшорными контрагентами являются факторами, которые могут привести к возникновению значительных правовых рисков для российских компаний.

\section{Заключение}

Итак, подводя итоги, нужно отметить, что офшорные схемы сулят российским компаниям значительные выгоды, связанные как с минимизацией налогообложения и незначительными административными барьерами, так и с защищенностью конфиденциальной информации об учредителях и лицах принимающих решения в хозяйствующих субъектах.

Существует множество способов использования офшорных компаний, но все их можно разделить на две большие группы: связанные минимизацией налогового бремени (уменьшение налогооблагаемой базы по налогу на прибыль или размера НДС в экспортных операциях) и связанные с выводом денежных средств с территории Российской Федерации.

Однако использование офшорных схем таит в себе множество опасностей. Так, лица, использующие офшорные фирмы и контролирующие их деятельность, рискуют быть привлеченными к налоговой, административной или уголовной ответственности. От этих видов ответственности не застрахованы и добросовестные предприниматели, не уделяющие должное внимание анализу контрагентов. Однако добросовестные предприниматели несут также серьезный гражданско-правовой риск, связанный с практической невозможностью эффективно защищать свои интересы в случае нарушения офшорной компанией своих обязательств.

\section{Библиография:}

1. Налоговый кодекс Российской Федерации (часть вторая) от 05.08.2000 N 117-Ф3.

2. Кодекс Российской Федерации об административных правонарушениях от 30.12.2001 N 195-Ф3. 


\section{Национальная безопасность 1(24) • 2013}

3. Уголовный кодекс Российской Федерации от 13.06.1996 N 63-Ф3.

4. Приказ Министерства финансов России от 13.11.2007 N 108H.

5. Письмо Минфина РФ от 23.02.1998 N 04-06-02.

6. Прудников П.В., Банк России вновь призывает коммерческие банки усилить контроль за клиентами, Новое в бухгалтерском учете и отчетности, 2008, N 21//СПС Консультант Плюс.

7. Удалов Р. Чем рискует контрагент офшорной компании // Налоги и налоговое планирование. 2011. N 5. C. $19-25$.

8. Павлов П.В. Офшорная деятельность: вопросы правовой регламентации // Журнал российского права. 2011. N 5. // СПС Консультант Плюс.

9. Гаврилова С. Офшоры: особенности правового регулирования // Финансовая газета. 2011. N 29. C. 12.

10. Панушко С., Шакирова М. Уголовно-правовые риски директоров и главных бухгалтеров в оф- шорных правоотношениях // Налоговый учет для бухгалтера. 2010. N 8. С. $34-42$.

\section{References (transliteration):}

1. Prudnikov P.V., Bank Rossii vnov' prizyvaet kommercheskie banki usilit' kontrol' za klientami, Novoe v buhgalterskom uchete i otchetnosti, 2008, N 21//SPS Konsul'tant Pljus.

2. Udalov R. Chem riskuet kontragent ofshornoj kompanii // Nalogi i nalogovoe planirovanie. 2011. N 5. S. 19-25.

3. Pavlov P.V. Ofshornaja dejatel'nost': voprosy pravovoj reglamentacii // Zhurnal rossijskogo prava. 2011. N 5. // SPS Konsul'tant Pljus.

4. Gavrilova S. Ofshory: osobennosti pravovogo regulirovanija // Finansovaja gazeta. 2011. N 29. S. 12.

5. Panushko S., Shakirova M. Ugolovno-pravovye riski direktorov i glavnyh buhgalterov $\mathrm{v}$ ofshornyh pravootnoshenijah // Nalogovyj uchet dlja buhgaltera. 2010. N 8. S. $34-42$. 